Использование традиционных САУ с поддержанием $\theta^{\text {зд }}$ и $\mathrm{I}^{\text {зд }}$ в окрестности фиксированных заданных значений не обеспечивает максимально возможную производительность пресс-гранулятора.

Использование СОЗ3 позволяет непрерывно оптимизировать $\theta^{\text {зд }}$ к окрестности оптимального значения $\theta$.

Использование СО33 дает возможность добиться максимальной производительности при низменном токе приводного электродвигателя прессуюшего узла.

Использование СО33 уменьшает удельные затраты электроэнергии на производство гранулированного комбикорма за счет оптимизации заданной температуры рассыпного комбикорма после тепловлажностной обработки паром в кондиционере-смесителе.

Система оптимизации заданного значения температуры рассыпного комбикорма после тепловлажностной обработки паром в кондиционере-смесителе может быть реализована как дополнение к традиционной системе в виде программного продукта.

Работа выполнена под руководством д.т.н. Хобина В.А.

\title{
Литература
}

1. Автоматизация комбикормовых заводов / Москаленко А.И., Птушкин А.Т., 1977. - С.205-216

2. Патент на полезную модель №36673 «Способ управления процессом гранулюрования комбикормов»/ Левинский В.М., Отрощенко С.Л., 2008г.

3. Патент на полезную модель №50838 «Способ автоматического управления процессом гранулирования комбикормовой массы в пресс-грануляторе»/ Старичков В.И., Диденко Д.В., 2010г.

4. Авторское свидетельство на изобретение №844380 «Устройство для автоматического управления прессгранулятором»/Долгозвяг В.А., Гончаренко А.Е., Редунов Г.М, Хобин В.А., Плеве А.Г., 1979г.

УДК 681.536.5: [631.563.9:725.36]

\section{РАЗРАБОТКА ГРАФИЧЕСКОГО ИНТЕРФЕЙСА ДЛЯ АВТОМАТИЗАЦИИ СИСТЕМЫ КОНТРОЛЯ ТЕМПЕРАТУРЫ ЗЕРНА В СИЛОСНЫХ КОРПУСАХ ЭЛЕВАТОРОВ}

\author{
Крутий Г.А., магистр \\ Одесская национальная академия пищевых технологий, Одесса
}

Современные средства программирования сегодня позволяют осуществлять удаленный контроль температуры в силосньх корпусах элеваторов с любой точки мира. Эта функция является дополнительной, она не обязательна, но почему не использовать эту возможность, когда она есть. Был проведен анализ и принято решение по созданию системы удаленного контроля, на основе шеb языков программирования, которая само собой имеет функиию удаленного доступа.

Modern software today allows remote control of temperature in the silo buildings with elevators all over the world. This feature is optional, it is not necessary, but why not uses this feature when it is. Analysis was conducted and the decision to establish a system of remote control, web-based programming language, which itself has the function of remote access.

Ключевые слова: контроль, зерно, элеваторы, температура, удаленный доступ, силосы, автоматизация

Сегодня в современных условиях сушествует много систем термометрии контроля температуры зерна. Некоторые из них:

- Система термометрии компании «Темикс» ИТУ-3

- Система термометрии компании «Нептун-Электро»

- Система термометрии компании «ИнноВиннпром»

- Система термометрии компании «ООО БРИЗ»

- Система термометрии компании «ШМИДТ-ЗИГЕР»

- Система термометрии разработанная в ОНАПТ

Они все высококачественные, осуществляют контроль температуры, выводят графики изменения температуры, но ни одна из них не позволяет осуществлять удаленный доступ через интернет, все заканчивается локальным компьютером.

В связи с выявленными недостатками систем, принято решение по разработке графического интерфейса для автоматической системы контроля температуры зерна в силосных корпусах элеваторов. За основу была взята система термометрии, которая была разработанная на кафедре Автоматизации Производственных Процессов, в Одесской национальной академии пищевых технологий. 


\section{СТУДЕНТСЬКА НАУКА}

Было принято решение, что создаваться система термометрии будет при помощи современных языков программирования:

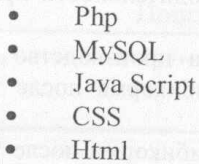

Таким образом, была поставлена задача:

Создание графического интерфейса для автоматической системы контроля температуры зерна в силосных корпусах элеваторов, доступ к которому может осуществляться с любой точки земного шара, при ситуации что (проверку) температулы инженер, находится вне зоны предприятия, и ему нужно осуществлять контроль данные на flash-носителе, либо использование такой систа латраты, для организации удаленного контроля,

Система обеспечивает регулярную передачу информации относительно значений температуры на термоподвесках. Далее за обработку данных отвечает рhр скрипт, который будет распределять, и передавать данные из базы данных в разрабатываемый графический интерфейс. Который в свою очередь сводит все в таблицу, и выводит графики изменения температуры за последние 30 дней.

\section{Функции системы:}

- Отображение на схеме предприятия силосы с цветом, который будет означать рабочую термоподвеску;

- Сведение всех данных базы данных в таблицу, по каждому силосу;

- Вывод графика изменения температуры за месяц по всем датчикам температуры на термоподвеске в нужном силосе,

- Авторизация пользователей, для защиты от несанкционированного входа в систему.

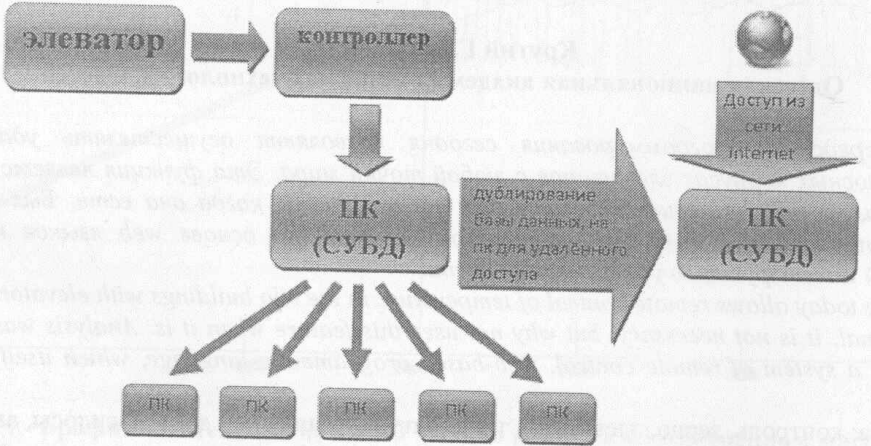

Рис.1 - структура организации передачи данных и контроля

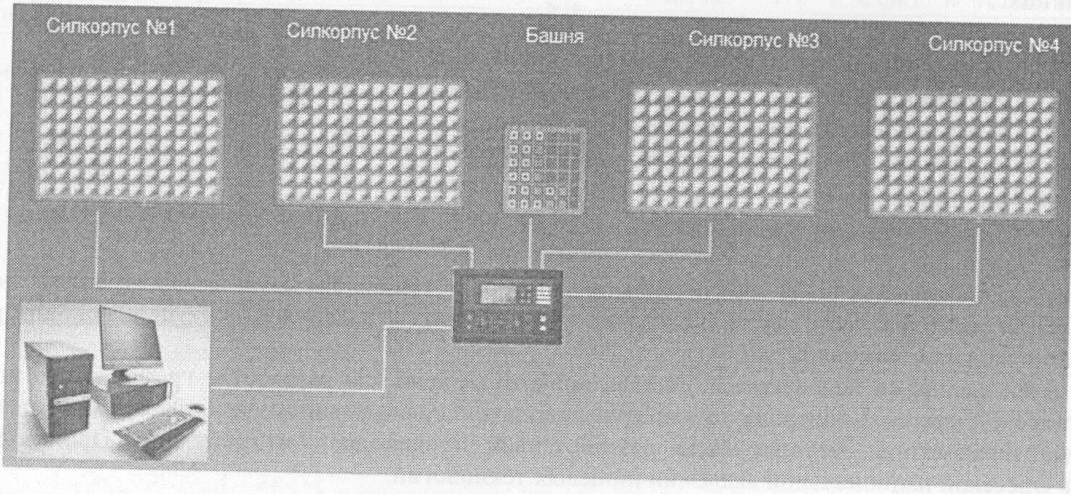

Рис.2 - Окно оператора, после входа в систему контроля 


\section{СТУДЕНТСЬКА НАУКА}

На рисунке 1 представлена структура передачи данных. На ней представлено 2 ПК, второй ПК служит страховкой, на который будет копироваться база данных, и уже непосредственно через него будет производиться удаленный доступ. Страховка нужна, что бы обезопасить себя от взлома, если он таки будет осуществлен, то вся база данных останется на первом ПК. На рисунке 2 представлено окно, которое видит перед собой оператор при входе в систему. Оно представляет из себя схему предприятия, которое имеет 4 силкорпуса и башню, все данные сводятся в контроллер, и дальше на ПІК. В ПК SCADA-система сводит все данные в базу MySQL. На рисунке 3 представлена развернутая схема силкорпуса, с показаниями температур. В каждом силосе указан номер, тип зерна и показания температуры последнее. Термоподвески, в которых произошло превышение границы температуры, показаны красным цветом. Рисунок 4 показывает фрагмент реализации графика изменения температуры за месящ.

\begin{tabular}{|c|c|c|c|c|c|c|c|c|c|c|c|}
\hline $\begin{array}{r}.3001 \\
+15 \\
\end{array}$ & $\begin{array}{r}\text { Nas002 } \\
-16\end{array}$ & $\begin{array}{r}163003 \\
+16 \\
6\end{array}$ & $\begin{array}{r}13004 \\
+16 \\
84,20+6\end{array}$ & $\begin{array}{r}163005 \\
713\end{array}$ & $\begin{array}{r}\text { No3006 } \\
+13\end{array}$ & $\begin{array}{r}\text { No8007 } \\
+13\end{array}$ & $\frac{1}{423016}$ & $\begin{array}{r}\text { No3009 } \\
+18 \\
\end{array}$ & $\begin{array}{r}\text { W3010 } \\
+13\end{array}$ & $\begin{array}{r}\text { No3011 } \\
+13 \\
\text { ruseyna }\end{array}$ & No3012 \\
\hline $\begin{array}{r}103013 \\
+13\end{array}$ & $\begin{array}{r}\text { Noso14 } \\
+18\end{array}$ & $\begin{array}{r}1103015 \\
-15\end{array}$ & $\begin{array}{r}103016 \\
+13\end{array}$ & $\begin{array}{r}103017 \\
+16 \\
4516046\end{array}$ & $\begin{array}{r}103018 \\
+16 \\
702018\end{array}$ & $\begin{array}{l}\mathrm{N} 23019 \\
=-13\end{array}$ & 183020 & $\mathrm{Na} 3021$ & $\begin{array}{l}\text { No3022 } \\
+45\end{array}$ & $\begin{array}{r}103023 \\
+13\end{array}$ & 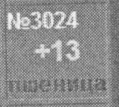 \\
\hline$\frac{163025}{-13}$ & $\begin{array}{r}113026 \\
+18 \\
\text { mone: }\end{array}$ & 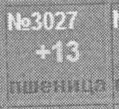 & $\begin{array}{c}\text { No3028 } \\
+18 \\
\text { nestinad }\end{array}$ & 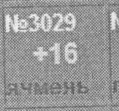 & $\begin{array}{r}\text { Wasoso } \\
-45\end{array}$ & 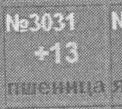 & $\frac{1}{123032}$ & $\frac{163082}{418}$ & 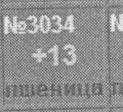 & now35: & 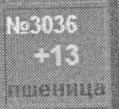 \\
\hline $\begin{array}{l}\text { Navos7 } \\
\text { mus }\end{array}$ & $\begin{array}{l}\text { No3083: } \\
\text { misewhua }\end{array}$ & $\begin{array}{l}13.3089 \\
\text { nureminaa }\end{array}$ & $\begin{array}{l}\text { ko3040 } \\
-18 \\
\text { menemina }\end{array}$ & 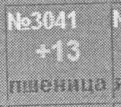 & 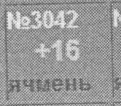 & 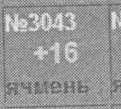 & 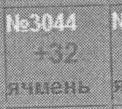 & 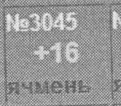 & 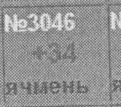 & 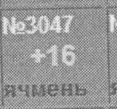 & $\begin{array}{l}\text { Nasmis } \\
+16 \\
\text { ячиень }\end{array}$ \\
\hline 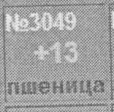 & $\begin{array}{l}\text { pesobu } \\
: 18 \\
\text { nue }\end{array}$ & 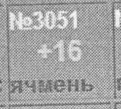 & $\begin{array}{l}\text { Mo3067 } \\
\text { nuenisua }\end{array}$ & $\begin{array}{c}158058 \\
+37 \\
\text { nuemuta }\end{array}$ & $\begin{array}{l}\text { Mososi } \\
\text { remennua }\end{array}$ & $\begin{array}{l}\text { Manso } \\
\text { muenwia }\end{array}$ & $\begin{array}{l}\text { moxiss } \\
\text { mumenuma }\end{array}$ & 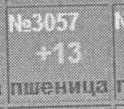 & $\begin{array}{l}\text { No3058 } \\
-216\end{array}$ & $\begin{array}{l}\text { Dososes } \\
\text { museница }\end{array}$ & $\begin{array}{l}\text { Mas060 } \\
\text { rumenma }\end{array}$ \\
\hline $\begin{array}{l}\text { Ig:075: } \\
\text { muernua }\end{array}$ & $\begin{array}{l}\text { bosoce? } \\
\text { nure }\end{array}$ & 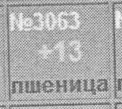 & 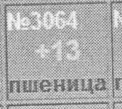 & 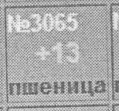 & 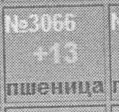 & 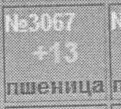 & $\begin{array}{l}\text { M. } 30685 \\
\text { nuenuцa }\end{array}$ & muemuцa & $\begin{array}{c}\text { nomo } \\
\text { nuеница }\end{array}$ & 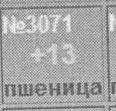 & 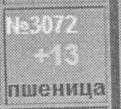 \\
\hline 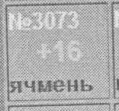 & 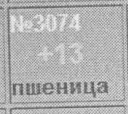 & $\begin{array}{l}\text { gromb } \\
\text { gqueнь }\end{array}$ & $\begin{array}{r}\text { frols } \\
+31 \\
\text { [nquemb }\end{array}$ & $\begin{array}{c}-x y 1 \\
+31 \\
\text { muеница }\end{array}$ & $\begin{array}{r}100: \\
+40 \\
\text { пименица }\end{array}$ & Im:еница & вичиень & \begin{tabular}{|c|}
8180 \\
nшенича
\end{tabular} & gчиень & 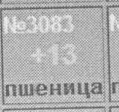 & 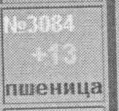 \\
\hline пшеница & 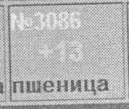 & 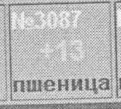 & пиеница & 9чиень & gчиень & 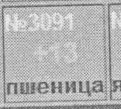 & 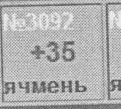 & ячимень & пшеница & пиеница & пиеница \\
\hline
\end{tabular}

Рис.3 - Показания температуры в каждом силосе

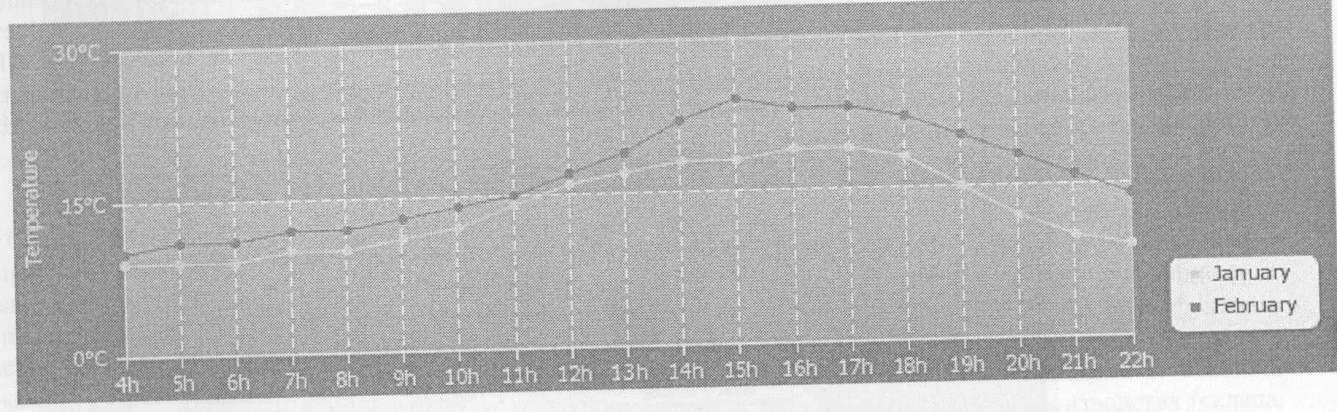

Рис. 4 - Фрагмент графика показываюшего изменения температуры за месяц в силосе

Дальнейшая работа над реализацией системы, будет продолжена в ходе дипломной работы.

Литература

1. Хобін В.А., Левінський В.М. Застосування тестового методу вимірювань в автоматизованих системах контролю температури зерна в силосах. - Наукові праці Одеської національної академії харчових технологій. - Одеса: 2003. - Вип. 26. - стор. 185-187. 
2. Термоподвески ЗАО «Темикс»-[ http://www.temix.com.ua ].

3. Построение графиков на языке php - [ http://pchart.sourceforge.net/screenshots.php?ID=24\#].

4. Справочник по языку разметки $\mathrm{html}$ - HTMLBOOK - [ http://htmlbook.ru ].

5. Системы термометрии: [ http://www.briznsk.ru/clauses/termometry.php ]; [ http://innovinnprom.com/sistemadkt.htm ]; [ http://termopodveska.com/production/tss 02.php ]; [ http://www.temix.com.ua/index.php?pages=1 ].

\title{
OБЗОР MES CИСТЕМЫ SIMATIC IT
}

\author{
Танчик C.B., магистр \\ Одесская национальная академия пищевых технологий, Одесса
}

Произведен обзор программного комплекса SIMATIC IT компании Siemens, который предназначен для создания MES систем для широкого спектра отраслей. Показано, что с помочью этого программного продукта можно создать MES систему, которая выполняет моделирование производственньх проиессов, определяет их возможности и получает данные с ERP уровня и уровня производства в реальном масштабе времени.

The review of program complex SIMATIC IT of Siemens which is intended for creation MES systems for a wide spectrum of branches is made. With this software product is possible to create MES system which carries out modeling of productions, defines their possibilities and obtains data with ERP level and a level of production in real time.

Ключевые слова: Siemens, SIMATIC IT, MES система, управление, моделирование.

Система оперативного управления производством (MES) - это динамическая информационная система, управляющая эффективным исполнением производственных операций. Термин MES охватывает целый класс систем, решающих задачи исполнения производства, такие как детальное планирование производства, й й отслеживание производства, анализ производительности, учет простоев, отслеживание качества продукции (LIMS), управление производственными фондами (EAM), управление запасами материалов и готовой продукции и т.д. [1]. Используя точные текущие данные, MES регулирует, инищиирует и протоколирует работу предприятия по мере возникновения событий. Набор функций MES позволяет управлять производственными операциями от момента появления заказа на производстве до доставки готового продукта. обо всей досавлет наиболее важную информацию о производственной деятельности для всей организации и бо всей цепочке поставок посредством двустороннего взаимодействия [2].

На Рис.1 представлено место, занимаемое MES в рамках концепции комплексной автоматизации TIA (Totally Integrated Automation), развиваемой фирмой Siemens. Согласно этому принципу локальные системы служат источниками данных для системы более высокого уровня, предоставляя ей требуемую информацию и, возможно, получая назад управляющие команды.

Отличие MES от ERP систем состоит в том, что в MES системах используется оперативная информация Отличие MES от SCADA систем состоит в том, что для исполнения производственных операций требуется управление работой многих единиц оборудования на различных участках производства. Обычно B SCADA системе модель контролируемого процесса явно не задается. Наличие большого количества оборудования, взаимосвязей и скрытых правил заставляет создавать явную модель производства, которая лежит в основе MES
системы и является ее неотъемлемой частью.

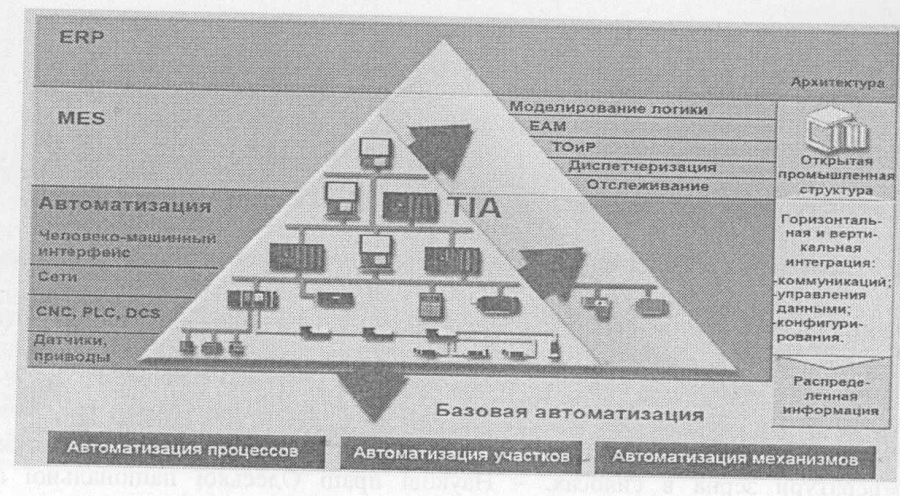

Рис. 1 - Комплексная автоматизация 